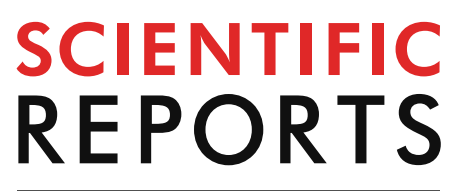

natureresearch

Check for updates

\title{
OPEN The impact of vitamin D supplementation on VDR gene expression and body composition in monozygotic twins: randomized controlled trial
}

\author{
Jeane Franco Pires Medeiros ${ }^{1 \bowtie}$, Michelle Vasconcelos de Oliveira Borges ${ }^{1}$, \\ Aline Alves Soares ${ }^{1}$, Jessica Cavalcante dos Santos ${ }^{2}$, Ana Beatriz Bezerra de Oliveira², \\ Conceição Horrana Belo da Costa ${ }^{2}$, Marina Sampaio Cruz ${ }^{1}$, Raul Hernandes Bortolin ${ }^{4}$, \\ Renata Caroline Costa de Freitas ${ }^{4}$, Paulo Moreira Silva Dantas ${ }^{1}$, Mario Hiroyuki Hirata ${ }^{4}$, \\ Vivian Nogueira Silbiger ${ }^{3,5}$ \& André Ducati Luchessi ${ }^{1,3,5}$
}

Vitamin D supplementation is widely used. However, there is no consensus on the use and dosage of this supplement and the existing recommendations arise from studies based on the benefits that this nutrient can facilitate in bones. In addition, individual genetics can influence the response to supplementation, therefore, research involving monozygotic twins aims to reduce these differences in phenotypic responses. The objective of this randomised controlled study is to examine the effect of vitamin $D$ supplementation on body composition and the expression of the vitamin $D$ receptor (VDR) mRNA. An intervention was performed through supplementation with cholecalciferol at the concentration of $2000 \mathrm{IU}$ in 90 healthy adult monozygotic twins (male or female pairs) for 2 months. The findings showed that serum vitamin $D$ concentration increased by $65 \%$ and VDR gene expression sixty times $(p=0.001)$. Changes in body composition parameters were observed regarding body fat and lean mass. Our results indicate that an increase in serum vitamin $D$ concentration may have potential therapeutic implications.

Supplementation with vitamin D (cholecalciferol) has become a widely used practice, since a relationship has been demonstrated of low levels of this nutrient with the increased risk of cardiovascular diseases, the recurrence of diseases, and mortality ${ }^{1,2,3}$. However, as there is no consensus on sufficient serum levels of vitamin $\mathrm{D}$, taking into account its non-skeletal functions, it is necessary to assess whether the increase in this nutrient in individuals with 25-hydroxyvitamin D (25 (OH) D) levels above the current cut-off point, generates any health benefits ${ }^{4}$.

Vitamin D is involved in several non-skeletal functions, such as cell regulation, differentiation, and growth ${ }^{3}$, and adaptive and innate immunity control ${ }^{5}$, as well as being associated with inflammatory markers ${ }^{6}$, since the vitamin $\mathrm{D}$ receptor $(V D R)$ is expressed in almost all human cells ${ }^{7}$. The activity of this nutrient in the human organism involves its binding with $V D R^{8}$, whose expression is modulated by the blood levels of the 1,25 diidroxivitamin $\mathrm{D}(1,25(\mathrm{OH}) 2 \mathrm{D})^{9}$ and genetic variants ${ }^{10}$.

It is believed that there is a negative correlation between the concentration of $25(\mathrm{OH}) \mathrm{D}$ with the body mass index (BMI) and percentage of fat mass ${ }^{11}$. However, few studies have comprehensively evaluated the effect of

\footnotetext{
${ }^{1}$ Department of Health Sciences, Federal University of Rio Grande Do Norte, Av. General Cordeiro de Farias, S/N Petrópolis, Natal, RN 59012-570, Brazil. ²Department of Pharmaceutical Sciences, Faculty of Pharmacy, Federal University of Rio Grande Do Norte, Natal, RN, Brazil. ${ }^{3}$ Graduate Program in Pharmaceutical Sciences, Faculty of Pharmacy, Federal University of Rio Grande Do Norte, Natal, RN, Brazil. ${ }^{4}$ Department of Clinical and Toxicological Analyses, School of Pharmaceutical Sciences, University of Sao Paulo, Sao Paulo, SP, Brazil. ${ }^{5}$ Department of Clinical and Toxicological Analyses, Federal University of Rio Grande Do Norte, Natal, RN, Brazil. ${ }^{\square}$ email: jeanefpires@hotmail.com
} 
increasing vitamin $\mathrm{D}$ concentration on body composition ${ }^{1}$, and no studies have analyzed the associated gene expression. In addition, clinical studies with monozygotic twins (MZ) are molecular models that allow evaluation of phenotypic aspects with minor interference related to individual genetic variability ${ }^{12,13}$, since MZ twins come from the same zygote ${ }^{14}$. Thus, a gene expression study of vitamin D supplementation in this population is an innovative idea, since individual genetic variations influence serum levels of this micronutrient ${ }^{15,16}$.

The aim of this study is to evaluate the effect of cholecalciferol supplementation on genic expression of the genes $V D R, T N F a$, and PPARa and body composition in MZ twins.

\section{Methods}

Study design and participants. This is a randomized clinical trial in pairs of MZ twins. This was a blind study, where each individual received an identification code, so that the researchers responsible for collecting data, carrying out tests, and analyzing the results did not know who had received the supplement. Twins who participated in the 1st Rio Grande do Norte Twin Festival were included in the study. The zygosity of the twins was determined by means of the zygosity questionnaire ${ }^{17}$. Eligibility criteria included pairs of twins of the same sex, from 18 to 45 years of age (to decrease the age gradient), twins who did not use vitamin supplements, with no diagnosis of chronic non-communicable diseases, and non-smokers. Individuals who were users of illicit drugs, those using supplements containing vitamin D including pregnant women, nursing mothers, and patients with metallic implants and pacemakers, that make it impossible to perform the Dual Energy X-ray absorptiometry test were excluded from the study. No amendments were made to the protocol of the research after the initiation of the trial and follow-up.

This study was approved by the Research Ethics Committee of the Federal University of Rio Grande do Norte (UFRN), protocol number 1.385.218, CAAE 51186615.5.0000.5292, which follows the resolutions of the National Research Ethics Commission of Brazil, in accordance with the principles of the Declaration of Helsinki. It was also approved by the Brazilian Registry of Clinical Trials under registration number RBR-3qy2f2 (date of registration 28/03/2016). All experiments were performed in accordance with relevant guidelines and regulations.

All participants were informed of the research objectives by responsible researchers and informed consent was obtained from each one. Their personal information was kept confidential.

Randomization. Randomization occurred by lot, performed centrally between 06 June 2016 and 21 December 2018 (at the Laboratory of movement at the Federal University of Rio Grande of Norte) using computer generated sequences stratified for twin 1 and twin 2, where each pair of twins received a numeric code and was separated, with one twin allocated to the control group (CG, without intervention) and the other to the supplemented group (SG, with intervention). The researcher responsible for the registration of the participants and for generating the randomisation and allocation of the assigned intervention were unique and different. The last follow-up occurred on February 21, 2019. In total, 94 eligible twins were recruited, and after being given information about the study, 90 individuals ( $73 \%$ women and $27 \%$ men) agreed to participate through written consent. There was sample loss only for analysis of gene expression of 40 individuals, since they did not return for collection regarding this analysis. However, to obtain a statistical power of 0.958 , using the values of Mean and Standard Deviation, at least 25 individuals are required before supplementation and 25 individuals after supplementation in these analyzes. In the other variables evaluated the 90 individuals remained from beginning to end. The study complied with the Consolidated Standards of Reporting Trials-CONSORT (Fig. 1).

The twins included in the SG received 60 capsules containing cholecalciferol with a concentration of $2000 \mathrm{IU}$ each, and were instructed to ingest one capsule per day for 60 days. This concentration does not exceed the maximum tolerable daily intake limit (UL), which is $4,000 \mathrm{IU} /$ day $^{18}$, in addition to being considered a dose for maintaining adequate levels of vitamin $\mathrm{D}$ in individuals after treatment for deficiency of this nutrient ${ }^{4}$.

At the beginning of the research, the primary endpoint was considered as the variation in the serum concentration of $25(\mathrm{OH}) \mathrm{D}$ after 60 days of supplementation with cholecalciferol. Our secondary endpoint was the variation in gene expression and body composition after 60 days of cholecalciferol supplementation.

During the intervention period, the twins maintained their usual routine, without dietary, sports, or lifestyle changes. After 30 days of inclusion in the study, participants from both groups were interviewed by a phone call to confirm appropriate capsule intake and for routine maintenance. All participants received a follow-up form to daily record when they ingested each capsule. Sixty days after the start of supplementation, these forms were returned to the researchers.

Body composition. Body composition was estimated by Dual Energy X-ray absorptiometry, performed using Lunar Prodigy Densitometer equipment, Model NRL 41990 (GE Lunar, Madison, WI, USA). The body mass index (BMI), total body fat and by body part, total lean mass and by body part, and bone mineral density (BMC) were measured on the day of inclusion in the study (T0, time 0 ) and 60 days after the first analysis (T60, time 60) in all participants in the CG and SG groups.

To calculate the BMI, height and body weight were measured using a stadiometer.

Sun exposure and skin phototype. The assessment of sun exposure was obtained through a score corresponding to the 7 days prior to the date of the bone densitometry evaluation ${ }^{19}$. The use of sunscreen was also recorded. The skin phototype was classified according to a questionnaire proposed by Fitzpatrick ${ }^{20}$.

Biochemical and vitamin D measurement. Peripheral blood samples were obtained after a 12-h fast in all participants in the CG and SG groups at T0 and T60. Glucose levels, total cholesterol, high-density lipoprotein (HDL), triglycerides, alanine aminotransferase (ALT), aspartate aminotransferase (AST), total proteins, 


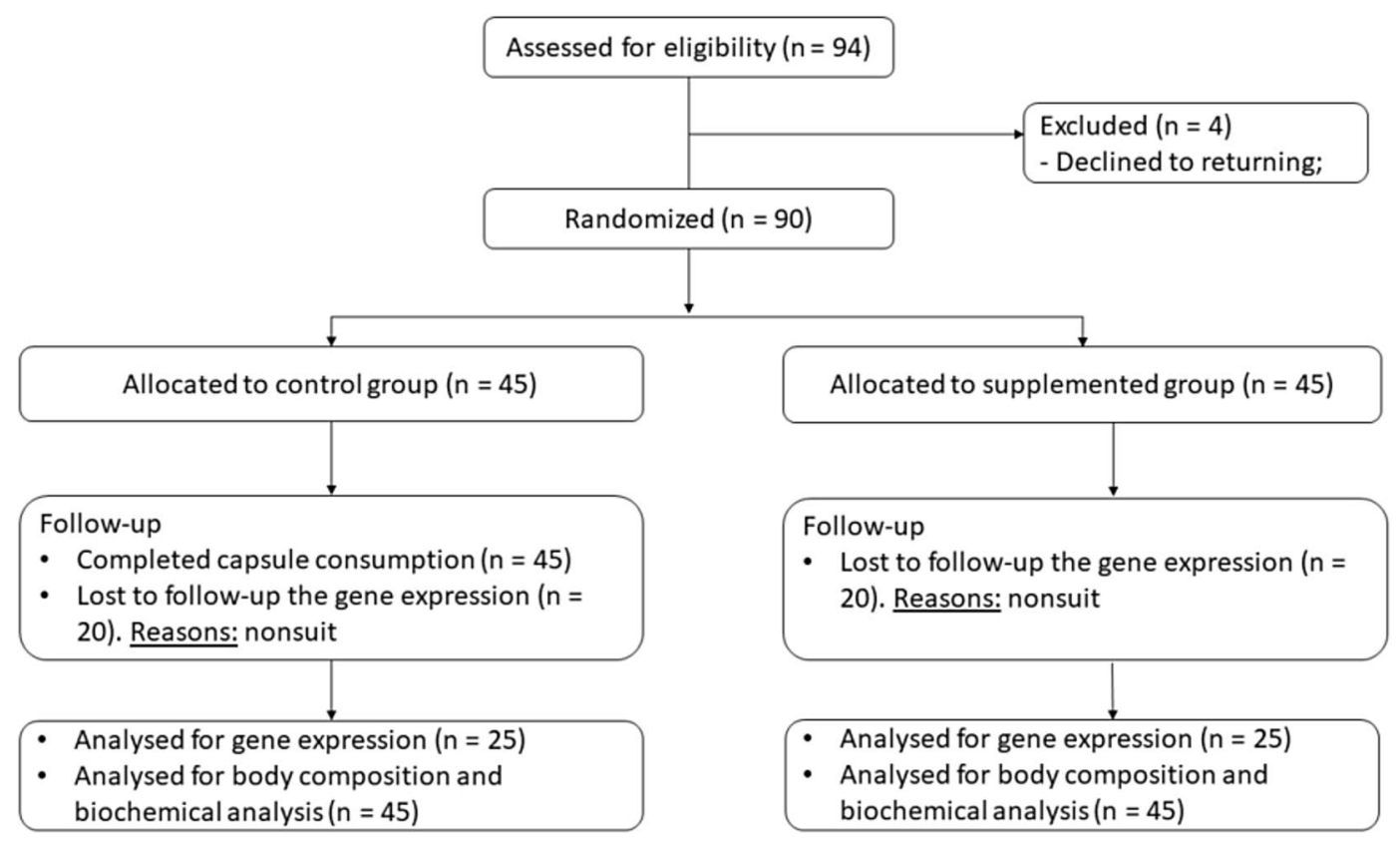

Figure 1. CONSORT diagram of participants of the randomized trial. Flow diagram of the study design. Dropouts from the study occurred due to giving up on returning for collection.

creatinine K, and uric acid were measured using Labtest kits (Lagoa Santa, Brazil) and Labmax Plenno equipment (Labtest, Lagoa Santa, Brazil).

The serum concentration of 25-hydroxyvitamin D $(25(\mathrm{OH}) \mathrm{D})$ was measured by chemiluminescence (Access 2, Beckman Coulter, United States). Values below $20 \mathrm{ng} / \mathrm{mL}$ were considered as deficiency and values between 20 and $29 \mathrm{ng} / \mathrm{mL}$ as insufficiency ${ }^{4}$.

RNA extraction. $4,0 \mathrm{~mL}$ of peripheral blood samples were collected from patients in tubes containing EDTA and leukocytes were isolated by centrifugation $(1,340 \times g, 15 \mathrm{~min})$ for gene expression analysis. Total RNA was extracted from leukocytes conserved in RNAlater stabilization solution (Invitrogen, California, USA) using Trizol reagent (Thermo Fisher, Waltham, MA, USA) according to the manufacturer's protocol. RNA quantification and purity were assessed by spectrophotometry using a Nanodrop ND-1000. RNA samples were stored at $-80^{\circ} \mathrm{C}$ until RT-qPCR analysis.

RNA expression by RT-qPCR. cDNA was synthesized with $50 \mu \mathrm{g}$ of total RNA using the High-Capacity cDNA Reverse Transcription Kit (Thermo Fisher, Waltham, MA, USA), in a MyCycler Thermal Cycler (Bio-Rad, Philadelphia, PA, USA), according to the manufacturer's protocol, and stored at $-20^{\circ} \mathrm{C}$.

RT-qPCR was carried out in 384-well plates using specific primers for Vitamin D Receptor Proteins (VDR), Peroxisome Proliferator Activated Receptor Alpha (PPARa), Tumor Necrosis Factor Alpha (TNFa), Actin Beta $(A C T B)$ and the QuantiTect SYBR Green PCR Kit (Qiagen GmbH, Hilden, Germany) (Supplementary Table 2 for sequence).

The qPCR assays were performed in a Quant Studio 12 K Flex Real-Time PCR System (Applied Biosystems, Forest City, USA). mRNAs with Ct-values $>35$ were excluded from the statistical analysis. Glyceraldehyde3-Phosphate Dehydrogenase (GAPDH), $18 \mathrm{~S} \mathrm{rDNA}$, and $A C T B$ were used as reference genes. According to the NormFinder algorithm, ACTB was the most stable gene under our experimental conditions, and thus it was used as the endogenous control. Relative expression was calculated by the $2^{-\Delta \Delta \mathrm{Ct}}$ method $^{21}$, using the nonsupplemented group as the control.

Statistical analysis. Distribution of variables was analyzed using the Kolmogorov-Smirnov test. Medians and quartiles are used to describe non-normally distributed data and absolute number and percentages to describe categorical data. The Mann-Whitney test was utilized to analyze the difference in independent group samples and the Wilcoxon test for dependent samples to verify intragroup differences. For categorical samples, the Chi-Square test was performed.

Statistical analysis was performed using the statistical software IBM SPSS version 20.0 for Windows (SPSS Inc., Chicago, IL, USA). All differences were considered significant when $p \leq 0.05$. 


\begin{tabular}{|c|c|c|c|}
\hline & CG & SG & \\
\hline & $(n=45)$ & $(n=45)$ & $p$ value \\
\hline Age, years & $24.0(21.0-27.0)$ & $24.0(21.0-27.0)$ & \\
\hline \multicolumn{4}{|l|}{ Education level $n,(\%)$} \\
\hline Incomplete secondary education & $1.0(2.2)$ & $1.0(2.2)$ & \\
\hline Complete secondary education & $8.0(17.8)$ & $10.0(22.2)$ & \\
\hline Incomplete higher education & $12.0(26.7)$ & $18.0(40.0)$ & \\
\hline Complete higher education & $14.0(31.1)$ & $12.0(26.7)$ & \\
\hline Postgraduate & $10.0(22.2)$ & $4.0(8.9)$ & 0.386 \\
\hline \multicolumn{4}{|l|}{ Family income level $n,(\%)$} \\
\hline$<1$ Minimum wage & $5.0(11.1)$ & $0.0(0.0)$ & \\
\hline$>3<5$ Minimum wages & $12.0(26.7)$ & $11.0(24.4)$ & \\
\hline$>5<7$ Minimum wages & $9.0(20.0)$ & $3.0(6.7)$ & \\
\hline$>7<10$ Minimum wages & $7.0(15.6)$ & $7.0(15.6)$ & \\
\hline$>10<20$ Minimum wages & $3.0(6.7)$ & $9.0(20.0)$ & \\
\hline$>20$ Minimum wages & $4.0(8.9)$ & $4.0(8.9)$ & \\
\hline Does not know & $3.0(6.7)$ & $7.0(15.6)$ & \\
\hline Did not answer & $2.0(4.4)$ & $4.0(8.9)$ & 0.065 \\
\hline Wears sunscreen $n,(\%)$ & $10.0(22.2)$ & $11.0(24.4)$ & \\
\hline Does not wear sunscreen $n,(\%)$ & $35.0(77.8)$ & $34.0(75.6)$ & 0.758 \\
\hline
\end{tabular}

Table 1. General characteristics of the twins in the study. Categorical variables are shown as number (percentage) and compared by chi-square test. Continuous variables are shown as median (percentile 25percentile 75) and compared by Wilcoxon test. CG, Control group; SG, Supplemented group; BMI, body mass index; BMC, bone mineral density. Brazilian minimum wage per month $=$ US\$265.73.

\section{Results}

Baseline characteristics. In total, 90 twins completed the study (see CONSORT diagram, Fig. 1). The rate of adherence and fidelity to capsule consumption was $100 \%$ in the SG $(n=45)$. Participants who ingested the 2000 IU cholecalciferol supplement reported no side effects. Sample collections took place in the years 2018 and 2019.

Socioeconomic data, including schooling and family income, were not significantly different between the CG and SG (Table 1). The most prevalent phototype of skin in this study was phototype 3 (light brunette skin, moderately burning and tanning, normal sensitivity to the sun). The sun exposure score was 16 at time 0 and time 60 in both groups. Over $70 \%$ of the total subjects did not use sunscreen daily, and those who did restricted use to the face.

Body composition and biomarkers. No variables analyzed showed intergroup differences at T0 $(p>0,05)$. After supplementation there were changes in the results of body composition in the SG. In the CG, total body fat did not vary in relation to time 0 and time $60(p=0.639)$, and in the SG there was a decrease in the final median $(p=0.259)$. The percentage of total fat, android fat, and gynoid fat decreased significantly in the SG. The gynoid lean mass increased in both groups, however this increase was significant in the SG $(p=0.007)$. Intragroup bone mineral density did not change from time 0 to time 60 (CG, $p=0.233$; SG, $p=0.433$ ) (Table 2).

Three subjects in the CG presented deficiency in serum concentrations of $25(\mathrm{OH}) \mathrm{D}$ at time 0 , and after 60 days one additional subject presented insufficiency. The subject received guidance on the use of vitamin D supplementation after completion of the research. Regarding the SG, only two subjects were classified as deficiency in $25(\mathrm{OH}) \mathrm{D}$ at the beginning of supplementation (60 days), and at the end of supplementation, with the dose used in this study (2000 IU cholecalciferol), no subjects presented insufficient serum concentrations of 25 $(\mathrm{OH}) \mathrm{D}$. No subject presented potentially toxic concentrations of 25-hydroxy-vitamin D.

The concentration of $25(\mathrm{OH}) \mathrm{D}$ in the serum increased in the SG in relation to the initial value $(>50 \mu \mathrm{g} / \mathrm{d})$. Comparing the groups separately, the total cholesterol, triglycerides, ALT, uric acid, and creatinine demonstrated analytical and biological variation after 2 months, without pathologic significance. However, when evaluating the difference in biomarkers between the CG and SG, no significant variations were found, with the exception of $25(\mathrm{OH}) \mathrm{D}$ (Table 3).

Gene expression. The mRNA expression was performed in $50 \mathrm{MZ}$ twins, 25 in the CG and 25 in the SG, as shown in (Fig. 2). Of the 3 genes analyzed in this study, mRNA expression of VDR increased significantly after 2 months of supplementation with 2000 IU cholecalciferol in the SG when compared with the CG $(p=0.001$ and $p=0.023$, respectively) (Supplementary Table 1 for sequence). 


\begin{tabular}{|c|c|c|c|c|c|c|c|c|c|c|}
\hline & \multicolumn{4}{|l|}{ CG $(n=45)$} & \multicolumn{4}{|l|}{ SG $(n=45)$} & \multicolumn{2}{|c|}{ CG (T60) x SG (T60) } \\
\hline & \begin{tabular}{|l|} 
T0 \\
\end{tabular} & T60 & Effect size & $p$ value & T0 & T60 & Effect size & $p$ value & Effect size & $p$ value \\
\hline BMI, $\left(\mathrm{kg} / \mathrm{m}^{2}\right)$ & $25.5(21.3-30.5)$ & $25.5(20.5-30.1)$ & 0.218 & 0.614 & $24.9(22.1-33.9)$ & $24.5(21.6-33.8)$ & 0.222 & 0.602 & 0.019 & 0.782 \\
\hline Total body fat, (kg) & $18.1(15.3-25.6)$ & $18.1(14.9-24.9)$ & 0.054 & 0.639 & $19.2(15.8-24.3)$ & $18.6(15.1-23.8)$ & 0.116 & 0.259 & 0.042 & 0.812 \\
\hline Total body fat, (\%) & $29.9(26.3-36.8)$ & $30.7(26.6-38.5)$ & 0.048 & 0.758 & $32.3(27.2-37.7)$ & $30.5(26.7-36.9)$ & 0.120 & 0.001 & 0.013 & 0.977 \\
\hline Arm Fat, (\%) & $31.3(25.9-38.0)$ & $32.2(26.1-39.5)$ & 0.037 & 0.554 & $33.5(27.8-40.8)$ & $33.9(27.3-40.3)$ & 0.043 & 0.390 & 0.072 & 0.583 \\
\hline Trunk Fat, (\%) & $30.4(24.9-36.4)$ & $30.3(25.1-36.4)$ & 0.001 & 0.758 & $31.8(25.7-38.4)$ & $31.4(27.7-36.9)$ & 0.015 & 0.228 & 0.138 & 0.506 \\
\hline Android fat, (\%) & $29.8(22.7-38.4)$ & $27.2(22.2-38.4)$ & 0.074 & 0.360 & $31.7(23.0-38.2)$ & $29.8(25.3-37.5)$ & 0.050 & 0.001 & 0.113 & 0.548 \\
\hline Gynoid Fat, (\%) & $35.8(29.5-42.3)$ & $34.7(29.6-43.4)$ & 0.006 & 0.831 & $37.9(30.8-43.0)$ & $36.5(29.8-41.5)$ & 0.094 & 0.005 & 0.049 & 0.687 \\
\hline Leg Fat, (\%) & $33.5(27.7-40.7)$ & $32.7(28.2-40.6)$ & 0.030 & 0.097 & $35.4(29.7-40.3)$ & $35.0(30.1-40.0)$ & 0.001 & 0.692 & 0.122 & 0.480 \\
\hline $\begin{array}{l}\text { Total Lean Mass, } \\
(\mathrm{kg})\end{array}$ & $39.0(35.1-45.5)$ & $38.6(34.7-47.6)$ & 0.091 & 0.839 & $38.2(34.5-47.6)$ & $38.2(34.1-47.7)$ & 0.015 & 0.554 & 0.067 & 0.781 \\
\hline $\begin{array}{l}\text { Android Lean Mass, } \\
(\mathrm{kg})\end{array}$ & $26.2(22.5-31.8)$ & $26.3(22.7-32.3)$ & 0.017 & 0.906 & $26.2(22.5-31.6$ & $24.8(22.3-33.7)$ & 0.011 & 0.877 & 0.009 & 0.681 \\
\hline $\begin{array}{l}\text { Gynoid Lean Mass, } \\
\text { (kg) }\end{array}$ & $61.1(53.8-74.8)$ & $62.0(56.0-74.5)$ & 0.005 & 0.616 & $58.3(51.8-68.9)$ & $59.6(52.9-70.4)$ & 0.052 & 0.007 & 0.193 & 0.362 \\
\hline BMC, (g) & $\begin{array}{l}2,248.5(2060.7- \\
2,558.5)\end{array}$ & $\begin{array}{l}2,182.5(2,309.0- \\
2,542.8)\end{array}$ & 0.056 & 0.233 & $\begin{array}{l}2,298.0(2007.0- \\
2,837.5)\end{array}$ & $\begin{array}{l}2,197.0(1950.5- \\
2,976.8)\end{array}$ & 0.048 & 0.433 & 0.118 & 0.715 \\
\hline
\end{tabular}

Table 2. Body composition in monozygotic twin adults with and without cholecalciferol supplementation. Continuous variables are shown as median (percentile 25-percentile 75) and compared by Wilcoxon test (intra-group values) and Mann-Whitney test (inter-group values). CG, Control group; SG, Supplemented group; T0, first analysis; T60, analysis 60 days after the first; BMI, body mass index; BMC, bone mineral density.

\begin{tabular}{|c|c|c|c|c|c|c|c|c|c|c|}
\hline & \multicolumn{4}{|l|}{ CG $(n=45)$} & \multicolumn{4}{|l|}{ SG $(n=45)$} & \multicolumn{2}{|c|}{ CG (T60) $\times$ SG $($ T60) } \\
\hline & T0 & T60 & Effect size & $p$ value & T0 & T60 & Effect size & $p$ value & Effect size & $p$ value \\
\hline$\star 25(\mathrm{OH}) \mathrm{D}, \mathrm{ng} / \mathrm{mL}$ & $32.7(27.3-43.9)$ & $34.4(26.9-39.3)$ & 0.050 & 0.382 & $30.7(26.3-33.6)$ & $50.6(40.3-56.1)$ & 1.763 & $<0.001$ & 1.422 & $<0.001$ \\
\hline Total proteins, $\mathrm{g} / \mathrm{dL}$ & $7.4(6.9-8.1)$ & $7.3(6.5-7.9)$ & 0.469 & 0.189 & $7.3(7.0-8.1)$ & $7.3(6.5-7.7)$ & 0.409 & 0.138 & - & $0.729^{*}$ \\
\hline Glucose, mg/dL & $86.0(79.0-97.0)$ & $84.0(79.0-93.0)$ & 0.048 & 0.397 & $87.0(79.0-94.5)$ & $87.5(82.0-91.0)$ & 0.166 & 0.069 & 0.090 & 0.735 \\
\hline $\begin{array}{l}\text { Total cholesterol, } \\
\mathrm{mg} / \mathrm{dL}\end{array}$ & $164.0(143.0-188.0)$ & $165.0(144.0-182.0)$ & 0.281 & 0.022 & $165.0(138.5-185.5)$ & $155.0(129.0-173.5)$ & 0.431 & 0.003 & 0.237 & 0.236 \\
\hline $\begin{array}{l}\text { HDL cholesterol, } \\
\mathrm{mg} / \mathrm{dL}\end{array}$ & $38.0(30.0-51.0)$ & $45.0(33.0-57.0)$ & 0.414 & 0.076 & $38.0(31.5-51.0)$ & $41.0(34.5-52.3)$ & 0.349 & 0.080 & 0.026 & 0.886 \\
\hline $\begin{array}{l}\text { Triglycerides, } \\
\mathrm{mg} / \mathrm{dL}\end{array}$ & $80.0(64.5-118.5)$ & $74.0(57.0-92.0)$ & 0.199 & 0.018 & $83.0(65.5-118.0)$ & $90.0(66.8-114.8)$ & 0.157 & 0.300 & 0.127 & 0.224 \\
\hline ALT, U/L & $19.0(12.5-31.0)$ & $17.0(12.0-22.0)$ & 0.246 & 0.058 & $17.0(11.5-31.0)$ & $14.5(11.0-20.8)$ & 0.391 & 0.017 & 0.137 & 0.099 \\
\hline AST, U/L & $20.0(17.0-24.0)$ & $19.0(14.0-23.0)$ & 0.184 & 0.314 & $19.0(16.0-28.0)$ & $18.5(15.8-25.3)$ & 0.372 & 0.070 & 0.098 & 0.477 \\
\hline Uric acid, mg/dL & $4.0(3.0-5.2)$ & $3.7(2.9-4.2)$ & 0.312 & 0.007 & $4.0(3.1-5.1)$ & $3.6(3.0-4.9)$ & 0.362 & 0.003 & 0.024 & 0.985 \\
\hline Creatinine, $\mathrm{mg} / \mathrm{dL}$ & $0.9(0.8-1.0)$ & $0.8(0.7-1.1)$ & 0.349 & 0.031 & $0.9(0.8-1.1)$ & $0.8(0.7-1.1)$ & 0.278 & 0.039 & 0.034 & 0.856 \\
\hline
\end{tabular}

Table 3. Serum concentrations of biochemical variables in monozygotic twin adults with and without cholecalciferol supplementation. Continuous variables are shown as median (percentile 25-percentile 75) and compared by Wilcoxon test (intra-group values) and Mann-Whitney test (inter-group values). CG, Control group; SG, Supplemented group; T0, first analysis; T60, analysis 60 days after the first; $25(\mathrm{OH}) \mathrm{D}$, 25-hydroxyvitamin D, reference value: $>20 \mathrm{ng} / \mathrm{mL}$; Total proteins, reference value: 6.0-8.0 g/dL; Glucose, reference value: 70-99 mg/dL; Total cholesterol, reference value: $<200 \mathrm{mg} / \mathrm{dL}$; HDL, high-density lipoprotein, reference value: $>60 \mathrm{mg} / \mathrm{dL}$; Triglycerides, reference value: $<150 \mathrm{mg} / \mathrm{dL} ; \mathrm{ALT}$, alanine aminotransferase, reference value: men 11-45 U/L, woman 10-37 U/L; AST, aspartate aminotransferase, reference value: men 11-39 U/L, woman 10-37 U/L; Uric acid, reference value: $1.0-7.0 \mathrm{mg} / \mathrm{dL}$; Creatinine, reference value: men $0.70-1.20 \mathrm{mg} / \mathrm{dL}$, woman $0.53-1.00 \mathrm{mg} / \mathrm{dL}$. ${ }^{\star}$ It was not possible to calculate the effect size (equals values).

\section{Discussion}

The findings of this short-term longitudinal study demonstrated that cholecalciferol supplementation at a concentration of $2000 \mathrm{IU}$ increased circulating serum vitamin D levels and VDR mRNA expression, as well as decreasing the percentage of body fat in MZ. These results are innovative since, for the first time, the effect of an increase in vitamin D on mRNA expression and body composition was evaluated without genetic influence and the results collaborate with discussions about the ideal $25(\mathrm{OH})$ D cut-off point to be considered, since concentrations above $50 \mathrm{ng} / \mathrm{mL}$ brought beneficial consequences to the individual's health. 

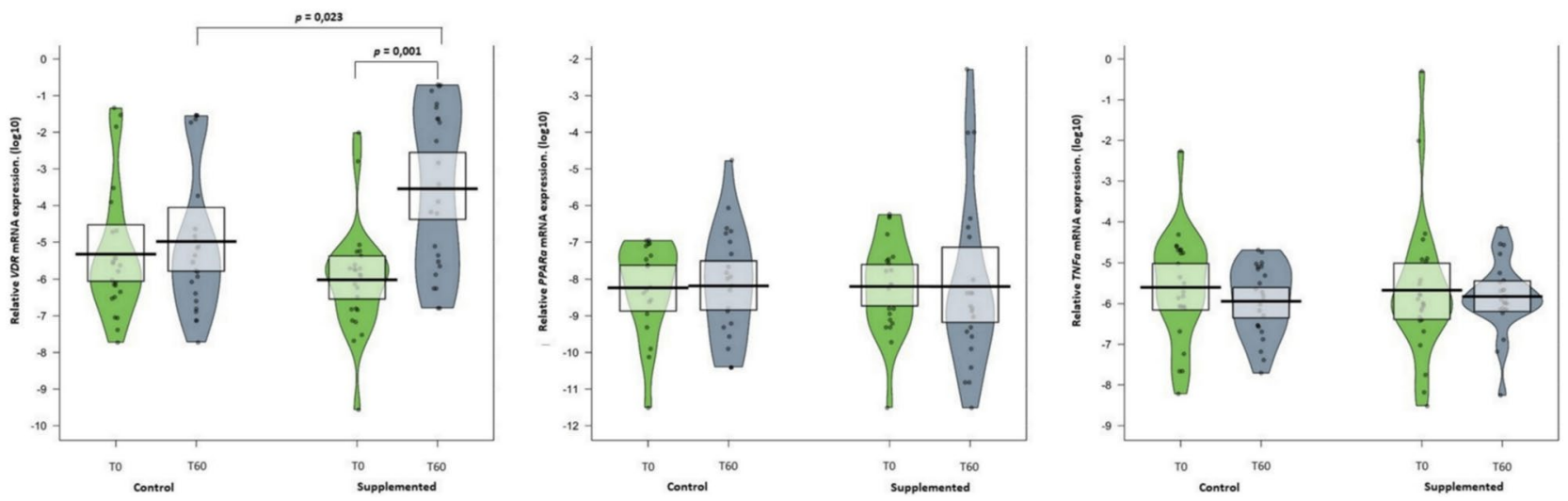

Figure 2. Median and distribution of VDR mRNA, TNFa mRNA, and PPARa mRNA expression in twins with and without supplementation with cholecalciferol. Data are shown as median (quartiles 1-3). Mann-Whitney $\mathrm{U}$ test was used to compare differences between independent groups (SG vs. CG). Wilcoxon test was used to compare intra-group values (T0 vs. T60). Vitamin D receptors (VDR); Tumor Necrosis Factor Alpha (TNFa); Peroxisome Proliferator Activated Receptor Alpha (PPARa).

The main objective of clinical research involving human beings is to improve prophylactic, diagnostic, and therapeutic procedures and to understand the etiology and pathogenesis of certain diseases. This studie provide us with greater understanding of these interactions, which may contribute to the development of strategies to combat diseases and promote health.

In Brazil, blood values of $25(\mathrm{OH}) \mathrm{D}$ greater than $20 \mathrm{ng} / \mathrm{mL}$ are considered sufficient ${ }^{22}$, however, worldwide, there are several parameters considered as sufficient values, varying from $>10 \mathrm{ng} / \mathrm{mL},>30 \mathrm{ng} / \mathrm{mL}$, and $>40 \mathrm{ng} /$ $\mathrm{mL}^{23}$. These recommendations were established based on studies on bone health, and, to date, there are no recommendations that take into account other benefits that vitamin $\mathrm{D}$ may bring to the individual.

Circulating levels of $25(\mathrm{OH}) \mathrm{D}$ correlate negatively with the body mass index and percentage of fat mass, since the higher the BMI and percentage of fat mass the lower the serum vitamin D concentration ${ }^{11,24}$. Obese healthy adults presented increased blood levels of $25(\mathrm{OH}) \mathrm{D}$ after weight loss over a 12 month period $^{25}$. In addition, although there is no clear evidence on the beneficial effect of vitamin D supplementation on metabolic parameters in obese individuals and weight $\operatorname{loss}^{26}$, our findings indicate a likely benefit for patients who need to decrease fat mass.

We present new evidence regarding the concentration of vitamin $\mathrm{D}$ and body composition, indicating that an increase in serum $25(\mathrm{OH}) \mathrm{D}$ concentration and expression of the VDR gene without weight loss, since the BMI did not change during the period of 2 months, contributes to the reduction in body fat and a slight increase in gynoid lean mass. Therefore, studying its molecular bases, metabolic pathways and interaction with tissues, such as adipose tissue, is needed to assist in future practical and clinical actions for the control of diseases that affect a large part of the population ${ }^{27}$.

A study that supplemented vitamin D for 6 months at 2,000 IU/day in 40 overweight and obese adults found no alterations in BMI and body fat percentage; however the analysis was performed using bioimpedance ${ }^{28}$. We evaluated body composition with the reference standard for the assessment of body composition ${ }^{29}$. On the other hand, after 24 weeks of supplementation with 60,000 IU/week of cholecalciferol, subcutaneous truncal fat reduced in overweight and obese pre-diabetic Asian women, with vitamin D deficiency ${ }^{1}$.

Fuller and collaborators ${ }^{30}$ showed that adults over the age of 45 who received supplements to increase lean mass only gained more strength when vitamin D levels were above $30 \mathrm{ng} / \mathrm{mL}$. After supplementation with $420 \mathrm{IU}$ cholecalciferol/day for 12 months, men and women presented significantly increased lean body mass (from $43.8 \pm 9.6$ to $44.3 \pm 9.8 \mathrm{~kg})^{31}$.

These findings may be related to the fact that the vitamin D receptor is present in almost all human tissues and mediates the vitamin $\mathrm{D}$ biological actions in adipose tissue, where it can be activated or inactivated ${ }^{32,33}$. VDR is a transcription factor that plays an important role in inducing the expression of several genes involved in the pathogenesis of obesity ${ }^{34}$.

Vitamin D and its metabolites belong to a small set of dietary compounds that have direct effects on gene regulation ${ }^{35}$. VDRs are critical for vitamin $\mathrm{D}$ to perform its functions, since the active form of this micronutrient 1,25-dihydroxy-vitamin $\mathrm{D}(1,25(\mathrm{OH}) 2 \mathrm{D})$, penetrates the cell membrane and binds to it. This complex interacts with the retinoic acid receptor (RXR) and forms heterodimers that act on target gene promoter regions, called vitamin $\mathrm{D}$ response elements, thus initiating a cascade of molecular interactions that regulate the transcription and suppression of specific genes ${ }^{36}$. VDRs have direct effects on the epigenome and expression of over 1,000 genes $^{37}$. This gene and its ligands antagonize proinflammatory transcription factors, such as NF-AT, AP-1, and $N F-\kappa B$ in T cells, which results in decreased expression of cytokines such as IL2 and $I L 12^{38}$.

A cohort study of 335 adults (age > 18 years old) with sickle cell anemia, followed at the Chicago Hospital in the United States, found that low vitamin D levels were associated with decreased VDR expression in peripheral blood mononuclear cells ${ }^{39}$. In white adipose tissue of obese rats, VDR gene expression increased after vitamin D supplementation of 50,1,000, or 10,000 IU/kg for 12 weeks ${ }^{40}$. In 110 patients with oral neoplastic lesions, premalignant lesions, and oral cancer, $V D R$ expression was increased, while insufficient or deficient blood levels of this 
micronutrient are prevalent in India ${ }^{41}$. On the other hand, a study on peripheral blood of 40 epileptic subjects found no significant correlation between vitamin D serum concentrations and VDR gene expression levels in $\mathrm{Iran}^{42}$. Tomaszewska, et al. ${ }^{43}$, after orally supplementing 16 patients with chronic rhinosinusitis with 1,000 IU of cholecalciferol for 1 month, in Warsaw, Poland, found no changes in VDR gene expression in sinonasal epithelial cells. These contradictory results indicate the importance of evaluating the effect of vitamin D supplementation in different population groups and on gene expression in different cell types and tissues.

Studies demonstrate that cholecalciferol can regulate gene expression by direct binding to VDR and that its affinity for VDR is several times higher than the active form of vitamin $\mathrm{D}(1,25-\mathrm{OH}$ vitamin $\mathrm{D})$ when bound to the vitamin D binding protein ${ }^{44,45}$. In humans, the Vitamin-D receptor (VDR) interacts with $1 \alpha, 25(\mathrm{OH}) 2 \mathrm{D} 3$ in the cell nucleus to generate genomic responses. ChIP-chip, ChIP-seq analyses and FAIRE-qPCR analyses have shown that, less than 1,000 sites are generally occupied by the VDR in the absence of $1 a, 25(\mathrm{OH}) 2 \mathrm{D} 3$ and nearly 9,000 sites are changed following $24 \mathrm{~h}$ treatment with the vitamin-D. In effect stimulation with active vitamin-D increases the chromatin accessibility for VDR and its signalling ${ }^{15,16,46}$.

Studies with MZ are of the utmost importance, since each pair comes from a single zygote and they present genetically identical elements, i.e., have the same genotype and constitute the only isogenic series in the human species. In twin studies, to assess the importance of genotype in determining the phenotype, the following assumptions are accepted, 1 . Twins are a sample of the general population, which is to say that among twins all characters are distributed in the same way as in the general population. 2 . The elements of each pair of twins are subject to the same environmental influences. 3. The environment of the twins is, on average, equal to that of the elements of the general population. By accepting these assumptions, one also accepts that the quantitative characters are determined solely by environmental factors in $\mathrm{MZ}^{14}$. Each pair of twins in this research had the same conditions and lifestyle as their sibling.

The supplementation dose used by the MZ in the current study is the recommended daily dose to maintain adequate serum values in adults (2000 IU/day), unlike most studies on vitamin D supplementation, which have been performed at doses of 1,000 IU/day for a period of 12 months $^{47}, 2000 \mathrm{IU} /$ day for 3 to 6 months $^{48,49}, 2,500 \mathrm{IU} /$ day for 4 or 6 months $s^{50,51}, 5,000 \mathrm{IU} /$ day for 3 months $^{52}, 40,000 \mathrm{IU} /$ weekly for a period of 2 months ${ }^{53}, 50,000 \mathrm{IU} /$ weekly in studies ranging from 5 to 6 months $\mathrm{s}^{5,55}$, and 100,000 IU/monthly from 2 to 12 months $\mathrm{s}^{56,57}$. A study developed with a maintenance dose of 2000 IU/day of vitamin D3 for 3 months in men and women who had been treated with 50,000 IU of vitamin D3 weekly for 3 months showed that this dose is not sufficient to maintain elevated levels of $25(\mathrm{OH}) \mathrm{D}$, however, serum values remained above $20 \mathrm{ng} / \mathrm{mL}^{58}$.

Experiments with vitamin D are aimed at population groups with $25(\mathrm{OH}) \mathrm{D}$ deficiency and some pathologies, such as diabetes, hypertension, insulin resistance, musculoskeletal disorders, cardiovascular disease, and kidney disease, as there is an association between low vitamin D levels and an increased risk of developing and worsening cardiovascular disease ${ }^{59}$, different types of cancers $^{60}$, diabetes $^{61}$, autoimmune diseases ${ }^{62}$, and overall mortality ${ }^{63}$. In addition, studies which used lower dosages of cholecalciferol were performed for periods longer than 2 months. For example, Lopez ${ }^{64}$ supplemented individuals with pre-diabetes with 2000 IU of cholecalciferol for 4 months and found a beneficial metabolic response, reducing circulating miR-7 and miR-192, accompanied by increased miR-152, which are useful biomarkers in prevention studies for diabetes.

Vitamin D has regulatory effects on innate and adaptive immunity and its receptor VDR is also expressed in cells of the immune system ${ }^{65}$. Therefore, the use of vitamin D3 and its analogues with other immunosuppressants has been studied synergistically or in isolation, in cases of autoimmune diseases, transplants, type 2 diabetes mellitus, and neoplasms ${ }^{66,67}$.

Pathogenic stimuli induce $T N F a$ expression, which in turn induces other mediators and proteases responsible for the inflammatory response ${ }^{68}$. Omidian ${ }^{69}$, supplementing diabetic patients with 4,000 IU/day of vitamin D for 3 months, found a significant difference in serum TNFa levels, showing the possible protective effect that this micronutrient can have on inflammation when used in larger dosages and for a prolonged period. Borges ${ }^{70}$ showed an association between vitamin D deficiency and reduced beta-oxidation markers, including PPARa. However, in the current research no significant association was found between 2000 IU cholecalciferol supplementation with TNFa or PPARa mRNA expression in MZ, possibly owing to the healthy population used.

The major limitations of the present study were the use of a single concentration of the supplement and evaluations performed with only 2 months of use, which did not enable us to address the long-term effects of this supplementation. The small sample size, as our pilot study population consisted of same-sex MZ twin siblings and the decrease in the sample number for analysis of gene expression. However, this was the first clinical trial with vitamin D supplementation evaluating gene expression in this study population. Thus, further studies with different concentrations and different supplementation times are necessary to confirm our hypothesis that the increase in the serum concentration of vitamin D possibly contributes to the fight against cardiovascular diseases through the reduction in body fat.

In conclusion, increasing serum $25(\mathrm{OH}) \mathrm{D}$ to values above $50 \mathrm{ng} / \mathrm{mL}$ yields health benefits through increased expression of VDR mRNA, reduced body fat, and increased lean mass, however, supplementation with $2000 \mathrm{IU}$ of cholecalciferol for 2 months did not alter TNFa or PPARa mRNA expression in twins.

\section{Data availability}

All datasets generated for this study are available from the corresponding author on direct request.

Received: 25 January 2020; Accepted: 7 July 2020

Published online: 20 July 2020 


\section{References}

1. Bhatt, S. P. et al. Vitamin D supplementation in overweight/obese Asian Indian women with prediabetes reduces glycemic measures and truncal subcutaneous fat: a 78 weeks randomized placebo-controlled trial (PREVENT-WIN Trial). Sci Rep. 10(1), 1-13 (2020).

2. Cho, Y. Y. \& Chung, Y. J. Vitamin D supplementation does not prevent the recurrence of Graves' disease. Sci Rep. 10(1), 1-7 (2020).

3. Feldman, D., Krishnan, A. V., Swami, S., Giovannucci, E. \& Feldman, B. J. The role of vitamin D in reducing cancer risk and progression. Nat. Rev. Cancer 14(5), 342-357 (2014).

4. Holick, M. F. et al. Evaluation, treatment, and prevention of vitamin D deficiency: an Endocrine Society clinical practice guideline. J. Clin. Endocrinol. Metab. 96(7), 1911-1930 (2011).

5. Chun, R. F., Liu, P. T., Modlin, R. L., Adams, J. S. \& Hewison, M. Impact of vitamin D on immune function: lessons learned from genome-wide analysis. Front. Physiol. 5, 151 (2014).

6. Dastan, F., Salamzadeh, J., Pourrashid, M. H., Edalatifard, M. \& Eslaminejad, A. Effects of high-dose Vitamin D replacement on the serum levels of systemic inflammatory biomarkers in patients with acute exacerbation of chronic obstructive pulmonary disease. COPD 16(3-4), 278-283 (2019).

7. Bouillon, R. et al. Vitamin D and human health: lessons from vitamin D receptor null mice. Endocr. Rev. 29(6), 726-776 (2008).

8. Christakos, S., Dhawan, P., Verstuyf, A., Verlinden, L. \& Carmeliet, G. Vitamin D: metabolism, molecular mechanism of action, and pleiotropic effects. Physiol. Rev. 96(1), 365-408 (2016).

9. Gupta, G. K., Agrawal, T., DelCore, M. G., Mohiuddin, S. M. \& Agrawal, D. K. Vitamin D deficiency induces cardiac hypertrophy and inflammation in epicardial adipose tissue in hypercholesterolemic swine. Exp. Mol. Pathol. 93(1), 82-90 (2012).

10. Abbassy, H. A., Elwafa, R. A. A. \& Omar, O. M. Bone mineral density and vitamin D receptor genetic variants in egyptian children with beta thalassemia major on vitamin D supplementation. Mediterr. J. Hematol. I 11(1), e2019013 (2019).

11. Muscogiuri, G. et al. Sex Differences of vitamin D status across BMI classes: an observational prospective cohort study. Nutrients 11(12), 3034 (2019).

12. Al-Daghri, N. M. et al. Efficacy of vitamin D supplementation according to vitamin D-binding protein polymorphisms. Nutrition 63, 148-154 (2019).

13. Yao, P. et al. A dose-response study of vitamin D3 supplementation in healthy Chinese: a 5-arm randomized, placebo-controlled trial. Eur. J. Nutr. 55(1), 383-392 (2016).

14. Beiguelman, B. The Study of Twins. 1th (ed. Ribeirão, P), pp 20-22 (São Paulo, 2008).

15. Vukić, M. et al. Relevance of vitamin D receptor target genes for monitoring the vitamin D responsiveness of primary human cells. PLoS ONE 10(4), e0124339 (2015).

16. Carlberg, C. \& Haq, A. The concept of the personal vitamin D response index. J. Steroid Biochem. Mol. Biol. 175, 12-17 (2018).

17. Ooki, S. \& Asaka, A. Zygosity diagnosis in young twins by questionnaire for twins' mothers and twins' self-reports. Twin Res. Hum. Genet. 7(1), 5-12 (2004).

18. Del Valle, H. B. et al. (eds) Dietary reference intakes for calcium and vitamin D (National Academies Press, Washington, 2011).

19. Hanwell, H. E. C. et al. Sun exposure questionnaire predicts circulating 25-hydroxyvitamin D concentrations in Caucasian hospital workers in southern Italy. J. Steroid Biochem. Mol. Biol. 121(1-2), 334-337 (2010).

20. Fitzpatrick, T. B. The validity and practicality of sun-reactive skin types I through VI. Arch. Dermatol. 124(6), 869-871 (1988).

21. Livak, K. J. \& Schmittgen, T. D. Analysis of relative gene expression data using real-time quantitative PCR and the $2^{-\Delta \Delta C T}$ method. Methods 25(4), 402-408 (2001).

22. Ferreira, C. E. S. et al. Consensus-reference ranges of vitamin D [25 (OH) D] from the Brazilian medical societies. Brazilian Society of Clinical Pathology/Laboratory Medicine (SBPC/ML) and Brazilian Society of Endocrinology and Metabolism (SBEM). J. Bras. Patol. Med. Lab. 53(6), 377-381 (2017).

23. Bouillon, R. Comparative analysis of nutritional guidelines for vitamin D. Nat. Rev. Endocrinol. 13(8), 466 (2017).

24. Rajakumar, K., De Las Heras, J., Lee, S., Holick, M. F. \& Arslanian, S. A. 25-Hydroxyvitamin D concentrations and in vivo insulin sensitivity and $\beta$-cell function relative to insulin sensitivity in black and white youth. Diabetes Care 35(3), 627-633 (2012).

25. Wamberg, L. et al. Expression of vitamin D-metabolizing enzymes in human adipose tissue-the effect of obesity and diet-induced weight loss. Int. J. Obes. 37(5), 651-657 (2013).

26. Bassatne, A. Vitamin D supplementation in obesity and during weight loss: a review of randomized controlled trials. Metabolism 92, 193-205 (2019).

27. Walsh, J. S., Bowels, S. \& Evans, A. L. Vitamin D in obesity. Curr. Opin. Endocrinol. Diabetes Obes. 24, 389-394 (2017).

28. Karefylakis, C. et al. Effect of Vitamin D supplementation on body composition and cardiorespiratory fitness in overweight men-a randomized controlled trial. Endocrine 61(3), 388-397 (2018).

29. Hind, K., Oldroyd, B. \& Truscott, J. G. In vivo precision of the GE Lunar iDXA densitometer for the measurement of total body composition and fat distribution in adults. Eur. J. Clin. Nutr. 65(1), 140-142 (2011).

30. Fuller, J. C. Jr. et al. Vitamin D status affects strength gains in older adults supplemented with a combination of $\beta$-hydroxy- $\beta$ methylbutyrate, arginine, and lysine: a cohort study. J. Parenter. Enter. Nutr. 35(6), 757-762 (2011).

31. Sun, X. et al. Effect of vitamin D supplementation on body composition and physical fitness in healthy adults: a double-blind. Randomized Controlled Trial Ann. Nutr. Metab. 75, 231-237 (2019).

32. Nguyen, V. T. et al. Vitamin D, inflammation, and relations to insulin resistance in premenopausal women with morbid obesity. Obesity. 23(8), 1591-1597 (2015).

33. Landrier, J. F., Karkeni, E., Marcotorchino, J., Bonnet, L. \& Tourniaire, F. Vitamin D modulates adipose tissue biology: possible consequences for obesity?. Proc. Nutr. Soc. 75(1), 38-46 (2016).

34. Trudler, D., Farfara, D. \& Frenkel, D. Toll-like receptors expression and signaling in glia cells in neuroamyloidogenic diseases: towards future therapeutic application. Mediators Inflamm. 2010, 1-12 (2010).

35. Carlberg, C. Nutrigenomics of vitamin D. Nutrients 11(3), 676 (2019).

36. Castro, L. C. The endocrinological system vitamin D. Arq. Bras. Endocrinol. Metab. 55(8), 566-575 (2011).

37. Carlberg, C. Vitamin D: a micronutrient regulating genes. Curr. Pharm. Des. 25(15), 1740-1746 (2019).

38. Zeitelhofer, M. et al. Functional genomics analysis of vitamin D effects on CD4+ T cells in vivo in experimental autoimmune encephalomyelitis $\square$. Proc. Natl. Acad. Sci. 114(9), e1678-e1687 (2017).

39. Han, J. et al. Risk factors for vitamin D deficiency in sickle cell disease. Br. J. Haematol. 181(6), 828-835 (2018).

40. Lee, G. Y. et al. Differential effect of dietary vitamin D supplementation on natural killer cell activity in lean and obese mice. J. Nutr. Biochem. 55, 178-184 (2018).

41. Anand, A. et al. Expression of vitamin D receptor and vitamin D status in patients with oral neoplasms and effect of vitamin D supplementation on quality of life in advanced cancer treatment. Contemporary Oncol. 21(2), 145 (2017).

42. Mazdeh, M. et al. Expression analysis of vitamin D signaling pathway genes in epileptic patients. J. Mol. Neurosci. 64(4), 551-558 (2018).

43. Tomaszewska, M. et al. Role of vitamin D and its receptors in the pathophysiology of chronic rhinosinusitis. J. Am. Coll. Nutr. 38(2), 108-118 (2019).

44. Munetsuna, E. et al. Anti-proliferative activity of 25-hydroxyvitamin D3 in human prostate cells. Mol. Cell Endocrinol. 382, 960-970 (2014). 
45. Verone-Boyle, A. R. et al. Diet-derived 25-hydroxyvitamin D3 activates vitamin D receptor target gene expression and suppresses EGFR mutant non-small cell lung cancer growth in vitro and in vivo. Oncotarget 7, 995-1013 (2016).

46. Giresi, P. G., Kim, J., McDaniell, R. M., Iyer, V. R. \& Lieb, J. D. FAIRE (formaldehyde-assisted isolation of regulatory elements) isolates active regulatory elements from human chromatin. Genome Res. 17(6), 877-885 (2007).

47. Breslavsky, A. et al. Effect of high doses of vitamin D on arterial properties, adiponectin, leptin and glucose homeostasis in type 2 diabetic patients. Clin. Nutr. 32(6), 970-975 (2013).

48. Moghassemi, S. \& Marjani, A. The effect of short-term vitamin D supplementation on lipid profile and blood pressure in postmenopausal women: a randomized controlled trial. Iran. J. Nurs. Midw. Res. 19(5), 517 (2014).

49. Ryu, O. H. et al. The effect of high-dose vitamin D supplementation on insulin resistance and arterial stiffness in patients with type 2 diabetes. Korean J. Intern. Med. 29(5), 620 (2014).

50. Gepner, A. D. et al. A prospective randomized controlled trial of the effects of vitamin D supplementation on cardiovascular disease risk. PLoS ONE 7(5), e36617 (2012).

51. Gepner, A. D. et al. A randomized controlled trial of the effects of vitamin D supplementation on arterial stiffness and aortic blood pressure in native American women. Atherosclerosis 240(2), 526-528 (2015).

52. Yiu, Y. F. et al. Randomized controlled trial of vitamin D supplement on endothelial function in patients with type 2 diabetes. Atherosclerosis. 227(1), 140-146 (2013).

53. Marckmann, P. et al. Randomized controlled trial of cholecalciferol supplementation in chronic kidney disease patients with hypovitaminosis D. Nephrol. Dial. Transplant 27(9), 3523-3531 (2012).

54. Dreyer, G. et al. Ergocalciferol and microcirculatory function in chronic kidney disease and concomitant vitamin d deficiency: an exploratory, double blind, randomised controlled trial. PLoS ONE 9(7), e99461 (2014).

55. Larsen, T., Mose, F. H., Bech, J. N., Hansen, A. B. \& Pedersen, E. B. Effect of cholecalciferol supplementation during winter months in patients with hypertension: a randomized, placebo-controlled trial. Am. J. Hypertens. 25(11), 1215-1222 (2012).

56. Mcgreevy, C., Barry, M., Bennett, K. \& Williams, D. The effect of vitamin D replacement on arterial stiffness in an elderly community based population. Irish J. Med. Sci. 182, s234-s235 (2013).

57. Witham, M. D. et al. Cholecalciferol treatment to reduce blood pressure in older patients with isolated systolic hypertension: the VitDISH randomized controlled trial. JAMA Intern. Med. 173(18), 1672-1679 (2013).

58. Sadat-Ali, M., Al-Anii, F. M., Al-Turki, H. A., AlBadran, A. A. \& AlShammari, S. A. M. Maintenance dose of vitamin D: How much is enough?. J. Bone Metab. 25(3), 161-164 (2018).

59. Trehan, N., Afonso, L., Levine, D. L. \& Levy, P. D. Vitamin D deficiency, supplementation, and cardiovascular health. Crit. Pathw. Cardiol. 16(3), 109-118 (2017).

60. Mondul, A. M., Weinstein, S. J., Layne, T. M. \& Albanes, D. Vitamin D and cancer risk and mortality: state of the science, gaps, and challenges. Epidemiol. Rev. 39(1), 28-48 (2017).

61. Ali, M. I., Fawaz, L. A., Sedik, E. E., Nour, Z. A. \& Elsayed, R. M. Vitamin D status in diabetic patients (type 2) and its relation to glycemic control \& diabetic nephropathy. DMS Clin. Res. Rev. 13(3), 1971-1973 (2019).

62. Prietl, B., Treiber, G., Pieber, T. R. \& Amrein, K. Vitamin D and immune function. Nutrients 5(7), 2502-2521 (2013).

63. Zheng, Y. et al. Meta-analysis of long-term vitamin D supplementation on overall mortality. PLoS ONE 8(12), e82109 (2013).

64. Lopez, Y. O. N., Pittas, A. G., Pratley, R. E. \& Seyhan, A. A. Circulating levels of miR-7, miR-152 and miR-192 respond to vitamin D supplementation in adults with prediabetes and correlate with improvements in glycemic control. J. Nutr. Biochem. 49, 117-122 (2017).

65. Brennan, A. et al. Dendritic cells from human tissues express receptors for the immunoregulatory vitamin D3 metabolite, dihydroxycholecalciferol. Immunology 61(4), 457 (1987).

66. Bertolini, D. L. \& Tzanno-Martins, C. Review: immunomodulatory effects of vitamin D. J. Bras. Nefrol. 22(3), 157-161 (2000).

67. Illescas-Montes, R., Melguizo-Rodríguez, L., Ruiz, C. \& Costela-Ruiz, V. J. Vitamin D and autoimmune diseases. Life Sci. 233(15), 116744 (2019).

68. Balkwill, F. Tumor necrosis factor or tumor promoting factor?. Cytokine Growth Factor Rev. 13, 135-141 (2002).

69. Omidian, M. et al. Effects of vitamin D supplementation on circulatory YKL-40 and MCP-1 biomarkers associated with vascular diabetic complications: a randomized, placebo-controlled, double-blind clinical trial. DSM Clin. Res. Rev. 13(5), 2873-2877 (2019).

70. Borges, C. C., Salles, A. F., Bringhenti, I. \& Mandarim-de-Lacerda, C. A. Aguila MB (2018) Vitamin D deficiency increases lipogenesis and reduces beta-oxidation in the liver of diet-induced obese mice. J. Nutr. Sci. Vitaminol. 64(2), 106-115 (2018).

\section{Author contributions}

J.F.P.M.: participated in conception, design, acquisition of data, investigation and methodology of the study, analysis of data and drafted the work.M.V.deO.B.: participated in acquisition of data, investigation and methodology of the study and analysis of data. A.A.S.: participated in acquisition and analysis of data. J.C.S.: participated in acquisition and analysis of data. A.B.B.Oliveira: participated in acquisition and analysis of data. C.H.B.C.: participated in acquisition and analysis of data. M.S.C.: participated in analysis of data. R.H.B.: participated in analysis of data. R.C.C.F.: participated in analysis of data. P.M.S.D.: participated in acquisition and analysis of data. M.H.H.: participated in analysis of data. V.N.S.: participated in acquisition and analysis of data and reviewed the work. A.D.L.: participated in conception, design, acquisition of data, investigation and methodology of the study, analysis of data, interpretation of data, and reviewed the work.

\section{Competing interests}

The authors declare no competing interests.

\section{Additional information}

Supplementary information is available for this paper at https://doi.org/10.1038/s41598-020-69128-2.

Correspondence and requests for materials should be addressed to J.F.P.M.

Reprints and permissions information is available at www.nature.com/reprints.

Publisher's note Springer Nature remains neutral with regard to jurisdictional claims in published maps and institutional affiliations. 
(c) (i) Open Access This article is licensed under a Creative Commons Attribution 4.0 International cc) License, which permits use, sharing, adaptation, distribution and reproduction in any medium or format, as long as you give appropriate credit to the original author(s) and the source, provide a link to the Creative Commons license, and indicate if changes were made. The images or other third party material in this article are included in the article's Creative Commons license, unless indicated otherwise in a credit line to the material. If material is not included in the article's Creative Commons license and your intended use is not permitted by statutory regulation or exceeds the permitted use, you will need to obtain permission directly from the copyright holder. To view a copy of this license, visit http://creativecommons.org/licenses/by/4.0/.

(C) The Author(s) 2020 